\title{
Among-population variation in costs of reproduction in the long-lived orchid Gymnadenia conopsea: an experimental study
}

\author{
Nina Sletvold · Jon Ågren
}

Received: 19 January 2011/Accepted: 19 April 2011/Published online: 10 May 2011

(C) The Author(s) 2011. This article is published with open access at Springerlink.com

\begin{abstract}
A cost of reproduction in terms of reduced future performance underlies all life-history models, yet costs have been difficult to detect in short-term experiments with long-lived plants. The likelihood of detecting costs should depend on the range of variation in reproductive effort that can be induced, and also on the shape of the cost function across this range, which should be affected by resource availability. Here, we experimentally examined the effects of both reduced and increased fruit production in two populations of the long-lived orchid Gymnadenia conopsea located at sites that differ in length of the growing season. Plants that were prevented from fruiting produced more flowers in the population with a longer growing season, had higher survival in the other population, and grew larger compared to control plants in both populations. Fruit production was pollen-limited in both populations, and increased reproductive investment after supplemental hand-pollination was associated with reduced fecundity the following year. The results demonstrate that the shape of the cost function varies among fitness components, and that costs can be differentially expressed in different populations. They are consistent with
\end{abstract}

Communicated by Alice Winn.

\section{N. Sletvold $(\bowtie)$}

NTNU, Museum of Natural History and Archaeology,

7491 Trondheim, Norway

e-mail: nina.sletvold@vm.ntnu.no

J. Ågren

Plant Ecology and Evolution, Department of Ecology

and Genetics, EBC, Uppsala University, Norbyvägen 18 D,

75236 Uppsala, Sweden

e-mail: jon.agren@ebc.uu.se the hypothesis that differences in temporal overlap between allocation to reproduction and other functions will induce among-population variation in reproductive costs.

Keywords Fitness components - Hand-pollination · Life-history evolution $\cdot$ Reproductive allocation $\cdot$ Trade-off

\section{Introduction}

Life-history theory assumes a trade-off between current reproduction and future performance, i.e. a cost of reproduction (Stearns 1992). Yet our understanding of how costs of reproduction are expressed in plants and the shape of the cost function for different components of fitness is limited. Some empirical studies of plants have confirmed the existence of a cost of reproduction, but there are several exceptions (Obeso 2002). In observational studies, apparent absence of costs may be due to confounding effects of environmental heterogeneity that influence overall resource availability, or failure to consider all traits involved in allocation trade-offs. If variation in overall resource availability is large relative to variation in proportion of resources allocated to reproduction, costs of reproduction can be difficult to detect (van Noordwijk and de Jong 1986; Reznick 1992; King et al. 2010). Moreover, often more than two traits are likely to be involved in allocation tradeoffs and negative correlations are not necessarily expected between all pairs of traits (Ågren and Schemske 1993; de Jong 1993). However, experimental studies have also failed to detect costs of reproduction (Obeso 2002; Reekie and Avila-Sakar 2005), and additional information is needed on how estimates of costs depend on experimental approaches, fitness components considered, and environmental conditions. 
In experimental studies, the likelihood of detecting costs will depend on the range of variation in reproductive effort that can be induced experimentally, and on the shape of the cost-investment relationship across this range (Ågren and Willson 1994; Thompson and Eckert 2004). While several studies have demonstrated significant costs of increased reproductive effort after supplemental hand-pollination in species with low natural seed set (e.g. in deceptive orchids; Primack and Stacy 1998 and references therein), this approach has limited power if seed production is not limited by pollen deposition. Likewise, reduced reproductive effort through flower removal may have little effect in perennial species with low investment in reproduction, explaining the lack of documented effects in several studies (e.g. Fox 1995; Huhta et al. 2009). By including both experimental reduction and increase in reproductive effort in the experimental design, the likelihood of detecting costs of reproduction should increase (e.g. Snow and Whigham 1989; Garcia and Ehrlén 2002). Manipulation of reproductive investment in both directions also allows an assessment of whether the shape of the cost function varies markedly among fitness components, i.e. whether different fitness components are affected by an experimental increase and reduction in reproductive effort, respectively.

In several studies, costs of reproduction have been detected only for some of the fitness components considered (Ågren and Willson 1994; Henriksson and Ruohomäki 2000; Ehrlén and van Groenendaal 2001; Aragón et al. 2009). In long-lived species, fitness is expected to be more sensitive to changes in survival than to changes in growth or fecundity (Stearns 1992; Charlesworth 1994; Franco and Silvertown 1997), and reproductive investment should be maintained at a level that ensures high survival. An experimental manipulation of reproductive effort is thus more likely to reveal costs expressed as reduced growth and fecundity than as reduced survival. In accordance with theory, experimental studies of plants have reported negative effects of reproduction on growth and fecundity more frequently than negative effects on survival, but this may also reflect the fact that trade-offs involving survival rarely have been examined (cf. Appendix 1 in Obeso 2002).

Estimates of costs of reproduction should vary with environmental conditions. Costs have been predicted to be most evident in habitats with low resource availability or stressful conditions (Reznick 1985), and trade-offs should be strongest between functions that compete for resources at the same time (Bell and Koufopanou 1986). Costs of reproduction are therefore likely to vary with the length of the growing season, because with a shorter growing season the temporal overlap between allocation to current reproduction and allocation to future survival and reproduction should increase. However, few studies have examined costs of reproduction in multiple populations or environments, and available results are mixed. Reproductive costs were reduced at higher temperature in the alpine perennial herb Saxifraga stellaris (Sandvik 2001), but not in Parnassia palustris (Sandvik and Eide 2009). Some studies indicate that costs increase in less productive sites (Biere 1995) or when the resource acquisition capacity of plants is reduced by defoliation (e.g. Lubbers and Lechowicz 1989; Primack and Hall 1990), but in several studies, direct manipulation of resource availability did not result in accentuated costs in low-resource treatments (Cheplick 1995; Saikkonen et al. 1998; Ronsheim and Bever 2000; Thompson and Eckert 2004; but see Primack and Antonovics 1982).

In this study, we experimentally reduced and increased fruit production in the long-lived, rewarding orchid Gymnadenia conopsea, using two populations found at sites that differ in length of the growing season. We ask the following questions. (1) Is fruit production associated with reduced flower production in the same year (reflecting a within-year trade-off between fruit and flower production), and reduced survival, size and fecundity in the following year? (2) Do experimental increases and reductions in fruit production affect different components of fitness? (3) Are costs more pronounced at the site with a shorter growing season?

\section{Materials and methods}

Study species and field sites

Gymnadenia conopsea (L.) R. Br. is a terrestrial orchid, distributed across Eurasia (Hultén and Fries 1986). It occurs on calcareous soils in grazed meadows and margins of marshes and fens. The species is a long-lived perennial (cf. Øien and Moen 2002); 43\% of the plants present in a monitoring programme in 1990 were still alive 18 years later (average minimum life-span $=10.4, n=93$; Moen, Øien, Sletvold, unpublished data). The species is tuberous and non-clonal, and characterised by high fruit set (Lönn et al. 2006) and low probability of repeated flowering in subsequent years (Øien and Moen 2002). Individuals emerge aboveground in late May to early June, and flowering starts 3-4 weeks later. Plants produce a single inflorescence with ca. 10-70 nectariferous flowers that open acropetally. Flower primordia are formed in the autumn prior to flowering (N. Sletvold, personal observation), but the proportion of flower primordia developing into functional flowers varies, and is likely to depend on resource availability during the flowering period. G. conopsea is visited by diurnal and nocturnal visitors (Meyer et al. 2007). In the study populations, flower visitors include butterflies, hawkmoths and flies (Sletvold and Ågren 2010). G. conopsea is self-compatible, but depends 
on flower visitors for pollen transfer (Jersáková et al. 2010; N. Sletvold, unpublished data). Populations flower for about a month, and fruits mature 4-6 weeks after pollination.

The two study populations are located $145 \mathrm{~km}$ apart in two nature reserves in central Norway, situated at the transition between the middle boreal and north boreal vegetation zones (Moen 1999). The coastal Tågdalen population $\left(63^{\circ} 03^{\prime} \mathrm{N}, 9^{\circ} 05^{\prime} \mathrm{E}\right)$ is situated at $450 \mathrm{~m}$ a.s.l. and has an oceanic climate (annual precipitation 1,507 mm), while the inland Sølendet population $\left(62^{\circ} 40^{\prime} \mathrm{N}, 11^{\circ} 50^{\prime} \mathrm{E}\right)$ is found at $770 \mathrm{~m}$ a.s.l. and has a more continental climate (annual precipitation $670 \mathrm{~mm}$ ). Mean monthly effective temperature sums (ETS; cf. Laaksonen 1979) are similar in the two nature reserves in May-July, but higher at Tågdalen in August-September (Lyngstad 2010; modelled based on data collected at nearby meteorological stations in 1973-2008). The growing season (days between first and last 5-day period after snowmelt with a mean temperature above $5^{\circ} \mathrm{C}$ ) is on average 5.5 days longer in the Tågdalen nature reserve compared to the Sølendet nature reserve (estimates based on data from 1980 to 2007; Lyngstad 2010). However, the actual difference between the two study populations is likely to be considerably larger due to marked differences in local topography. The Tågdalen population is situated on a steep south-facing slope, while the Sølendet population is sloping gently eastward. The shorter growing season in the Sølendet population is likely to increase the temporal overlap between allocation to current reproduction and allocation to survival and future reproduction compared to the Tågdalen population, and reproductive costs should thus be more pronounced at the former site. Both populations are found in open, wet grasslands, dominated by Molinia caerulea (L.) Moench, Succisa pratensis Moench, and Thalictrum alpinum L.. The number of flowering G. conopsea individuals in 2008 and 2009 was approximately 200 and 400 in the Tågdalen population and 600 and 1,000 in the Sølendet population, respectively.

\section{Field experiment}

In June 2008, a total of 180 and 360 plants were individually marked in the two study populations Tågdalen and Sølendet, respectively. In both populations, one-third of the plants were randomly assigned to each of three treatments, (1) open-pollinated controls, natural level of reproductive allocation, (2) removal of all flowers, reduced reproductive allocation, and (3) supplemental hand-pollination, increased reproductive allocation. To quantify initial plant size, we counted the number of leaves and recorded maximum length and width of the two longest leaves of each plant at the start of the experiment. Populations were visited 1-3 times per week, and in the hand-pollination treatment, all open flowers were pollinated by hand with cross-pollen from the local population. All flowers received supplemental pollination at least once. In the flowerremoval treatment, we removed flower buds with scissors as they were about to open, and noted the total number of flowers removed. At the end of flowering, we recorded the total number of flowers and fruits in open- and hand-pollinated plants.

In June 2009, we relocated the marked plants and recorded their status (missing, vegetative, or flowering), and size. All missing individuals had an intact tag and were considered dead. We cannot exclude the possibility that some of the missing individuals were dormant rather than dead. However, long-term monitoring of individual plants in the study populations suggests that dormancy is rare (Moen, Øien, Sletvold, unpublished data). The annual rate of plant loss is low (mean $=5.3 \%, 1996-2006$ ) and no tubers were found in a previous attempt to excavate missing individuals in the Sølendet population $(n=6)$. We counted the number of leaves and measured maximum length and width of the two longest leaves on each living plant. At the time of fruit maturation, we recorded the total number of flowers and fruits produced by flowering individuals.

In both years, we estimated plant size as the product of number of leaves and mean leaf area. To quantify the increase in fruit production following supplemental handpollination, we calculated pollen limitation (PL) for each population as $1-$ (mean number of fruits produced by open-pollinated control plants/mean number of fruits produced by hand-pollinated plants).

\section{Statistical analyses}

We used two-way ANOVA to examine the effects of treatment and population on plant size (total leaf area) and number of flowers and fruits in the first year. To improve normality of residuals, plant size was log-transformed prior to analyses. The flower removal treatment was excluded in the analysis of fruit production.

We used linear models including initial plant size (leaf area in the first year) as a covariate to examine effects of population and treatment on plant size and fitness components in the second year. Survival and flowering propensity (flowering vs. non-flowering in the second year) were analysed with binomial errors and a logit link function (proc GENMOD; SAS 9.2; SAS Institute, Cary, NC, USA), while leaf area, and number of flowers and fruits (including only reproductive plants) were analysed with normal errors and identity link (proc GLM). To determine whether the cost of reproduction is size-dependent, we initially included the interaction between treatment and initial size in the 
statistical models. In the analysis of total leaf area, we initially included also reproductive status in the second year (flowering vs. non-flowering) and its interactions with population and treatment because leaf morphology differs considerably between vegetative and reproductive plants. Because interactions with initial size (all models) and with reproductive status (analysis of leaf area in the second year) were not statistically significant $(P>0.10)$, they were omitted from the final models. In cases with a significant treatment $\times$ population interaction, we proceeded with one-way ANOVA to examine effects of treatment within each study population. There was no mortality in the Tågdalen population, and the analysis of the effects of treatment on survival was therefore confined to the Sølendet population. In cases with a significant treatment effect, we performed post-hoc comparisons using the Tukey's test in GLM or the LSMEANS and DIFF options in GENMOD.

\section{Results}

Plant size and pollen limitation

Plants in the Tågdalen population were larger $\left(F_{1,520}=\right.$ 58.3, $P<0.0001$ ) and produced more flowers (Table 1; Fig. 1a) compared to plants in the Sølendet population, but plant size did not differ among treatments at the onset of the experiment $\left(F_{2,520}=1.64, P=0.20\right)$. In both populations, fruit set among open-pollinated control plants was high $(73-74 \%)$. Fruit production was pollenlimited (significant treatment effect, Table 1; PL $=0.13$ at Tågdalen vs. PL $=0.22$ at Sølendet), but the flower removal treatment represented a larger change in fruit production than did the supplemental hand-pollination (Fig. 1b).

\section{Costs of fruit production}

\section{Flower production in the year of the treatment}

The effect of experimental manipulation of fruit production on the number of flowers produced in the first year differed between the two populations (significant treatment $x$ population interaction; Table 1; Fig. 1a), with significant variation among treatments at Tågdalen (one-way ANOVA; $\left.F_{2,156}=3.43, P=0.035\right)$, but not at Sølendet $\left(F_{2,349}=0.23, P=0.80\right)$. In the Tågdalen population, plants that were prevented from fruiting tended to produce more flowers than plants in other treatments (Tukey $P<0.08$ for both comparisons; Fig. 1a).

\section{Survival and size in the second year}

Fruit production reduced plant size in the following year in both populations, and survival at Sølendet, the population with a shorter growing season. In the Sølendet population, plants that were prevented from fruiting had significantly higher survival than hand-pollinated plants (Table 1; $\left.\chi^{2}=9.38, P=0.0022\right)$, and also tended to have higher survival than open-pollinated controls $\left(\chi^{2}=3.81\right.$, $P=0.051$ ), whereas the difference between controls and hand-pollinated plants was not statistically significant $\left(\chi^{2}=1.70, P=0.19\right.$; Fig. $\left.1 \mathrm{c}\right)$. At Tågdalen, all plants were still alive in the second year (Fig. 1c). In both populations, plants that were prevented from fruiting had significantly larger leaf area than plants in the other treatment groups (Fig. 1d; Table 1; Tukey $P<0.0001$ for both

Table 1 Effects of treatment and population on measures of Gymnadenia conopsea performance in the first and second year examined with generalized linear models

\begin{tabular}{|c|c|c|c|c|c|c|c|c|c|c|}
\hline \multirow[t]{2}{*}{ Trait } & \multicolumn{2}{|c|}{ Treatment } & \multicolumn{2}{|c|}{ Population } & \multicolumn{2}{|c|}{ Treat $\times$ population } & \multicolumn{2}{|c|}{ Initial size } & \multicolumn{2}{|c|}{ Reproductive status year 2} \\
\hline & $F / \chi^{2}$ & $P$ & $F / \chi^{2}$ & $P$ & $F / \chi^{2}$ & $P$ & $F / \chi^{2}$ & $P$ & $F$ & $P$ \\
\hline No. of flowers year 1 & 2.89 & 0.057 & 71.3 & $<0.0001$ & 4.01 & 0.019 & & & & \\
\hline No. of fruits year $1^{\mathrm{a}}$ & 14.6 & 0.0002 & 8.19 & 0.0045 & 0.54 & 0.46 & & & & \\
\hline Survival year $1-2^{\mathrm{b}}$ & 9.51 & 0.0086 & & & & & 3.50 & 0.061 & & \\
\hline Leaf area year 2 & 58.7 & $<0.0001$ & 18.0 & $<0.0001$ & 0.82 & 0.44 & 206.8 & $<0.0001$ & 7.70 & 0.0058 \\
\hline Flowering year 2 & 8.10 & 0.017 & 0.05 & 0.83 & 0.94 & 0.62 & 16.1 & $<0.0001$ & & \\
\hline No. of flowers year 2 & 1.44 & 0.25 & 0.001 & 0.95 & 0.90 & 0.41 & 1.96 & 0.17 & & \\
\hline No. of fruits year 2 & 3.03 & 0.049 & 0.33 & 0.57 & 0.42 & 0.66 & 2.65 & 0.11 & & \\
\hline
\end{tabular}

Analyses of survival, leaf area, reproductive status, and number of flowers and fruits in the second year included initial size (leaf area in the first year) as a covariate, and the analysis of leaf area included also reproductive status in the second year as an independent variable. $P<0.05$ in $b o l d$

${ }^{\text {a }}$ Only hand-pollinated plants and controls

b Only the Sølendet population 
(a)
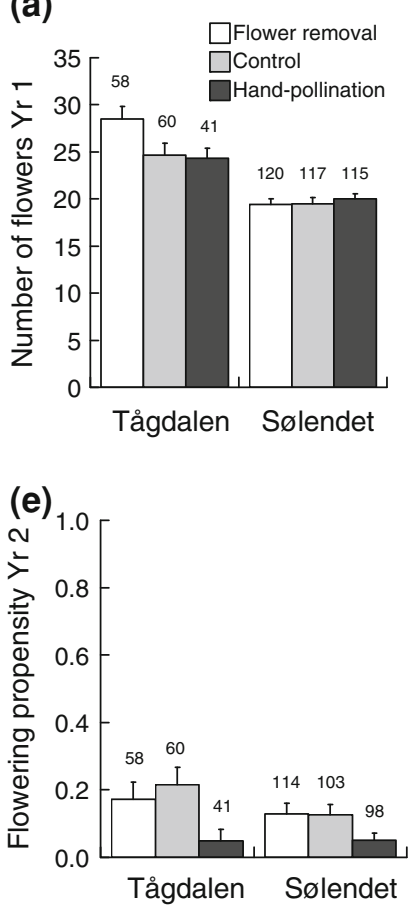

(b)

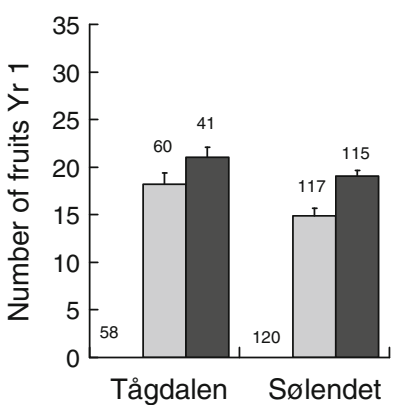

(f)

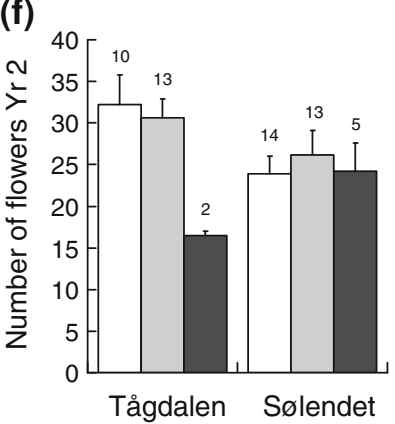

Fig. 1 The effect of reduced (flower removal) and increased (handpollination) reproductive effort on performance of two populations of Gymnadenia conopsea: a flower production and $\mathbf{b}$ fruit production in the first year, and $\mathbf{c}$ survival, $\mathbf{d}$ size, $\mathbf{e}$ flowering probability, $\mathbf{f}$ flower

comparisons), whereas no significant difference was found between controls and hand-pollinated plants (Tukey $P=0.72$ ). Initial size positively affected size in the following year, and the leaf area of reproductive plants was larger than that of vegetative plants (Table 1; mean leaf area $\pm \mathrm{SD}$, reproductive vs. vegetative, Tågdalen $36.2 \pm 15.4$ vs. $27.3 \pm 16.0 \mathrm{~cm}^{2}$, Sølendet $25.4 \pm 13.0$ vs. $\left.17.0 \pm 10.5 \mathrm{~cm}^{2}\right)$.

\section{Fecundity in the second year}

Few experimental plants flowered in $2009(<22 \%$ in all treatments), indicating a high cost of flowering. Flowering propensity was significantly lower among hand-pollinated plants compared to both open-pollinated controls (Fig. 1e; Table $\left.1 ; \chi^{2}=7.49, P=0.0062\right)$ and plants that were prevented from fruiting $\left(\chi^{2}=6.95, P=0.0084\right)$, but did not differ between the latter two treatments $\left(\chi^{2}=0.01\right.$, $P=0.93)$. Flowering propensity increased with initial size (Table 1). Among reproductive plants, flower production did not differ significantly between populations or treatments (Fig. 1f; Table 1), but fruit production was significantly lower among plants that were hand-pollinated in the preceding year compared to plants that were prevented from fruiting in the preceding year (Fig. 1g; Table 1; Tukey $P=0.042$ ). Fruit production of open-pollinated

(c)

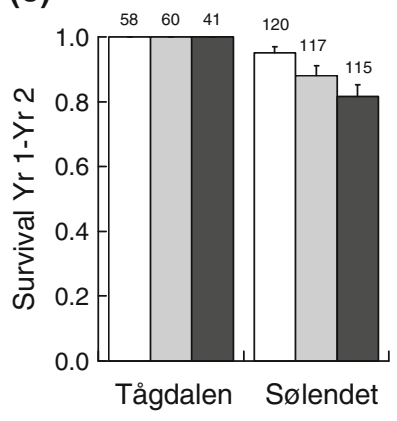

(d)

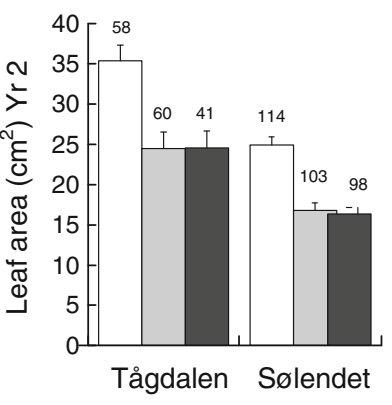

(g)

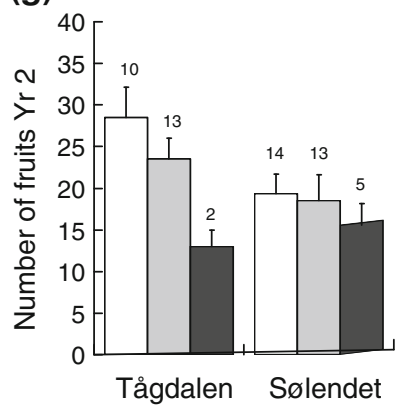

production, and $\mathbf{g}$ fruit production in the second year. Bars are means per individual (+SE). Sample size is indicated above each bar. Statistical analyses are reported in Table 1

controls did not differ significantly from that of the other treatment groups in the second year (Fig. 1g; Tukey $P>0.30)$.

\section{Discussion}

The orchid G. conopsea has a high fruiting success, and natural levels of fruit production incurred significant costs in terms of reduced flower production in the same year in the population with a longer growing season, reduced survival in the population with a shorter growing season, and reduced plant size in the following year in both populations. In contrast, fecundity costs were detected only after an experimental increase in fruit production, which reduced flowering propensity and fecundity the second year. These differences show that the shape of the cost function across the examined range in reproductive allocation varied among fitness components, and that costs can be expressed through different pathways in different populations and depending on the direction of change in current reproductive investment. Similar results have emerged from studies with birds, where experimental increases and reductions in reproductive effort have shown that the shape of cost functions may depend on the life-history trait considered and may differ between sexes (e.g. Jacobsen et al. 1995; Velando and Alonso-Alvarez 2003). 
The actual fitness components affected by the different manipulations were partly unanticipated. In G. conopsea, we expected reductions in reproductive effort to affect fecundity more strongly than survival, whereas the opposite was true in one of the study populations. Long-lived species are expected to maintain reproductive allocation within a range which ensures high probability of future survival (Clutton-Brock 1984), and survival may thus not respond readily to experimental manipulation of reproductive effort. Consistent with this prediction, even longterm experimental studies have failed to document survival costs in long-lived plants (Primack and Stacy 1998) and birds (Erikstad et al. 2009). Surprisingly, the present results indicate a significant survival cost of natural levels of fruit production in the Sølendet population of $G$. conopsea. The decrease in survival probability from 0.95 to 0.82 may seem modest, but the importance of survival for lifetime fitness should be high in long-lived perennials (Franco and Silvertown 1997). Long-term demographic studies suggest that dormancy is rare in the study population (Moen, Øien, Sletvold, unpublished data), but we cannot dismiss the possibility that some of the plants recorded as dead in the present study were actually dormant. This would represent a lower but not insignificant demographic cost of fruit production. Several studies indicate that dormancy per se involves costs (Hutchings 1987; Shefferson et al. 2003). We are presently collecting demographic data to determine whether selection favours reduced reproductive effort in the Sølendet population under current conditions.

Costs of reproduction were partly expressed through different fitness components in the two study populations. Among-site differences in the ways costs of reproduction are expressed have previously also been documented in the perennial herbs Primula veris (Syrjänen and Lehtilä 1993) and Ranunculus acris (Hemborg 1998), and the timing of cost expression varied among populations of the orchid Cypripedium acaule (Primack and Stacy 1998). A number of factors may cause among-population variation in cost expression. Costs may be reduced at productive sites (Reznick 1985; Biere 1995; Jacquemyn et al. 2010), or populations may differ in the timing of investment in competing functions (cf. Méndez 1999; Thompson and Eckert 2004), causing variation in the degree of temporal overlap between investments in growth, flowering and the production of storage organs. The Sølendet population is situated at higher altitude than the Tågdalen population, and experiences lower temperatures and a shorter growth period. More restrictive conditions are also indicated by the fact that plants at Sølendet produce fewer flowers and have lower survival compared to plants at Tågdalen. The shorter season should increase the temporal overlap between allocation to reproduction and allocation to storage and winter survival, and could explain why a survival cost was detected only in the Sølendet population, and why flower removal did not result in increased flower production at Sølendet, while it did so at Tågdalen. Numerous studies on birds and mammals have supported the prediction of higher costs of reproduction when conditions are adverse (see references. in Erikstad et al. 2009), but the evidence for this in plants remain unconvincing (Dostal et al. 2009; see "Introduction"). Manipulations of the environment in the two study populations could clarify which factors influence the expression of costs of reproduction in $G$. conopsea. There are as yet few experimental studies that include multiple populations, and additional work is needed to determine how the shapes of cost functions vary across environments.

There is some evidence that costs may be size-dependent (Worley and Harder 1996; Hemborg and Karlsson 1998; Jacquemyn et al. 2010), suggesting that amongpopulation variation in plant size may contribute to differential cost expression. However, in the present study, treatment effects did not vary with initial plant size (no significant interaction between treatment and size), and differences in cost expression between the two populations could not be explained by the difference in mean plant size.

We detected significant short-term costs of both natural and increased reproduction in the rewarding $G$. conopsea. Most previous experimental studies of costs of reproduction in orchids have been conducted on deceptive species, i.e. species which do not offer any reward to their pollinators, and which are characterized by low levels of natural fruit set (Primack and Stacy 1998 and references therein). These studies have consequently only examined costs associated with increased reproduction (but see Snow and Whigham 1989). The present results suggest that natural levels of fruit production are associated with a substantial cost, and also indicate that inflorescence production in itself is costly. Despite a higher number of flowering individuals in both study populations in the second year compared to the first, very few of the experimental plants flowered in the second year, and this was also true for plants that were prevented from producing any fruits in the first year. A significant cost of flower production has been demonstrated experimentally also in the woodland orchid Tipularia discolor (Snow and Whigham 1989). A low probability of repeated flowering in subsequent years has been reported in previous observational studies of $G$. conopsea (Øien and Moen 2002; Gustafsson 2007), and intermittent flowering is apparently typical for several temperate orchids (Wells and Willems 1991). The present results suggest that such intermittent flowering may be a function of costs associated with both flower and fruit production.

A full understanding of life-history evolution requires insights into trade-offs at both the phenotypic and genetic 
levels (Roff 2000, 2002). Experimental manipulation of reproductive investment to determine phenotypic trade-offs should thus ideally be combined with breeding designs or selection experiments to quantify genetic variances and covariances among life-history traits (Reznick 1985, 1992; Partridge and Harvey 1988). Because of their long juvenile period, and their rather specific demands on growth conditions, the genetic analysis of life-history trade-offs in orchids remains a major challenge.

To conclude, this study has demonstrated substantial short-term costs of both natural and increased levels of reproductive effort in the orchid $G$. conopsea, partly expressed through different paths. However, some costs may become evident only after several episodes of high reproductive investment, and some costs detected in shortterm experiments may be insignificant across the entire life history. Demographic data allowing the modelling of cost effects on lifetime fitness will therefore be required for a comprehensive understanding of how current reproduction affects future performance in this and other long-lived perennial plants.

Acknowledgments This study was financially supported by grants from the Norwegian Research Council to N.S., and from the Swedish Research Council to J.A. We thank J. M. Grindeland for assistance during field work, and A.A. Winn and two anonymous reviewers for helpful comments on the manuscript. Our work complied with the current laws of Norway.

Open Access This article is distributed under the terms of the Creative Commons Attribution Noncommercial License which permits any noncommercial use, distribution, and reproduction in any medium, provided the original author(s) and source are credited.

\section{References}

Ågren J, Schemske DW (1993) The cost of defense against herbivores: an experimental study of trichome production in Brassica rapa. Am Nat 141:338-350

Ågren J, Willson MF (1994) Costs of seed production in the perennial herbs Geranium maculatum and G. sylvaticum: an experimental field study. Oikos 70:35-42

Aragón CF, Méndez M, Escudero A (2009) Survival costs of reproduction in a short-lived perennial plant: live hard, die young. Am J Bot 96:904-911

Bell G, Koufopanou V (1986) The cost of reproduction. Oxford Surv Evol Biol 3:83-131

Biere A (1995) Genotypic and plastic variation in plant size: effects on fecundity and allocation patterns in Lychnis flos-cuculi along a gradient of natural soil fertility. J Ecol 83:629-642

Charlesworth B (1994) Evolution in age-structured populations. Cambridge studies in mathematical biology 1. Cambridge University Press, Cambridge

Cheplick GP (1995) Life history trade-offs in Amphibromus scabrivalvis (Poaceae): allocation to clonal growth, storage, and cleistogamous reproduction. Am J Bot 82:621-629

Clutton-Brock TH (1984) Reproductive effort and terminal investment in iteroparous animals. Am Nat 123:212-229 de Jong G (1993) Covariance between traits deriving from successive allocations of a resource. Funct Ecol 7:75-83

Dostal P, Havlíčková V, Jorritsma-Wienk LD, Eriksson O, Herben T (2009) Interspecific competition changes reproductive output but does not increase reproductive costs in a grassland perennial. Basic Appl Ecol 10:525-534

Ehrlén J, van Groenendaal J (2001) Storage and the delayed costs of reproduction in the understorey perennial Lathyrus vernus. J Ecol 89:237-246

Erikstad KE, Sandvik H, Fauchald P, Tveraa T (2009) Short- and long-term consequences of reproductive decisions: an experimental study in the puffin. Ecology 90:3197-3208

Fox JF (1995) Shoot demographic responses to manipulation of reproductive effort by bud removal in a willow. Oikos 72:283-287

Franco M, Silvertown J (1997) Life history variation in plants: an exploration of the fast-slow continuum hypothesis. In: Silvertown J, Harper JL (eds) Plant life histories: ecology, phylogeny and evolution. Cambridge University Press, Cambridge, pp 210-227

Garcia MB, Ehrlén J (2002) Reproductive effort and herbivory timing in a perennial herb: fitness components at the individual and population levels. Am J Bot 89:1295-1302

Gustafsson S (2007) Flowering frequency in a small population of Gymnadenia conopsea — a five year study. Nord J Bot 24:599-605

Hemborg ÅM (1998) Costs of reproduction in subarctic Ranunculus acris: a five-year field experiment. Oikos 83:273-282

Hemborg ÅM, Karlsson PS (1998) Altitudinal variation in size effects on plant reproductive effort and somatic costs of reproduction. Ecoscience 5:517-525

Henriksson J, Ruohomäki K (2000) Assessing costs of reproduction in mountain birch: the importance of considering the modular level. Ann Bot 86:503-510

Huhta AP, Rautio P, Hellström K, Saari M, Tuomi J (2009) Tolerance of a perennial herb, Pimpinella saxifraga, to simulated flower herbivory and grazing: immediate repair of injury or postponed reproduction? Plant Ecol 201:599-609

Hultén E, Fries M (1986) Atlas of north European vascular plants north of the tropic of cancer, vols 1-3. Koeltz, Königstein

Hutchings MJ (1987) The population biology of the early spider orchid, Ophrys sphegodes Mill.: II. Temporal patterns in behavior. J Ecol 75:729-742

Jacobsen K-O, Erikstad KE, Sæther B-E (1995) An experimental study of the costs of reproduction in the kittiwake Rissa tridactyla. Ecology 76:1542-1636

Jacquemyn H, Brys R, Jongejans E (2010) Size-dependent flowering and costs of reproduction affect population dynamics in a tuberous perennial woodland orchid. J Ecol 98:1204-1215

Jersáková J, Castro S, Sonk N, Milchreit K, Schödelbauerová I, Tolasch T, Dötterl S (2010) Absence of pollinator-mediated premating barriers in mixed-ploidy populations of Gymnadenia conopsea s.1. (Orchidaceae). Evol Ecol 24:1199-1218

King EG, Roff DA, Fairbairn DJ (2010) Trade-off acquisition and allocation in Gryllus firmus: a test of the Y model. J Evol Biol $24: 256-264$

Laaksonen K (1979) Effective temperature sums and durations of the vegetative period in Fennoscandia (1920-1950). Fennia 157:171-197

Lönn M, Alexandersson R, Gustafsson S (2006) Hybrids and fruit set in a mixed flowering-time population of Gymnadenia conopsea (Orchidaceae). Hereditas 143:222-228

Lubbers AE, Lechowicz MJ (1989) Effects of leaf removal on reproduction vs. belowground storage in Trillium grandiflorum. Ecology 70:85-96

Lyngstad A (2010) Population ecology of Eriophorum latifolium, a clonal species in rich fen vegetation. PhD dissertation, Norwegian University of Science and Technology, Trondheim 
Méndez M (1999) Effects of sexual reproduction on growth and vegetative propagation in the perennial geophyte Arum italicum (Araceae). Plant Biol 1:115-120

Meyer B, Kröger J, Steffan-Dewenter I (2007) Contribution of diurnal and nocturnal pollinators to the reproductive success of the orchid species Gymnadenia conopsea. Entomol Gen 30:299-300

Moen A (1999) National atlas of Norway: vegetation. Norwegian Mapping Authority, Hønefoss

Obeso JR (2002) The costs of reproduction in plants. New Phytol $155: 321-348$

Øien D-I, Moen A (2002) Flowering and survival of Dactylorhiza lapponica and Gymnadenia conopsea in the Sølendet Nature Reserve, Central Norway. In: Kindlmann P, Willems JH, Whigham DF (eds) Trends and fluctuations and underlying mechanisms in terrestrial orchid populations. Backhyus, Leiden, pp 3-22

Partridge L, Harvey PH (1988) The ecological context of life history evolution. Science 241:1449-1455

Primack RB, Antonovics J (1982) Experimental ecological genetics in Plantago. VII Reproductive effort in populations of $P$. lanceolata L. Evolution 36:742-752

Primack RB, Hall P (1990) Costs of reproduction in the pink lady's slipper orchid: a four year experimental study. Am Nat 136:638-656

Primack RB, Stacy E (1998) Costs of reproduction in the pink lady's slipper orchid (Cypripedium acaule, Orchidaceae): an elevenyear experimental study in three populations. Am J Bot 85:1672-1679

Reekie EG, Avila-Sakar G (2005) The shape of the trade-off function between reproduction and growth. In: Reekie EG, Bazzaz F (eds) Reproductive allocation in plants. Elsevier, San Diego, pp 189-214

Reznick D (1985) Cost of reproduction: an evaluation of the empirical evidence. Oikos 44:257-267

Reznick D (1992) Measuring the costs of reproduction. Trends Ecol Evol 7:42-49

Roff DA (2000) Trade-offs between growth and reproduction: an analysis of the quantitative genetic evidence. J Evol Biol 13:434-445

Roff DA (2002) Life history evolution. Sinauer, Sunderland
Ronsheim ML, Bever JD (2000) Genetic variation and evolutionary trade-offs for sexual and asexual reproductive modes in Allium vineale (Liliaceae). Am J Bot 87:1769-1777

Saikkonen K, Koivunen S, Vuorisalo T, Mutikainen P (1998) Interactive effects of pollination and heavy metals on resource allocation in Potentilla anserina. Ecology 79:1620-1629

Sandvik SM (2001) Somatic and demographic costs under different temperature regimes in the late-flowering alpine perennial herb Saxifraga stellaris (Saxifragaceae). Oikos 93:303-311

Sandvik SM, Eide W (2009) Costs of reproduction in cicumpolar Parnassia palustris L. in light of global warming. Plant Ecol 205:1-11

Shefferson RP, Proper J, Beissinger SR, Simms EL (2003) Life history trade-offs in a rare orchid: the costs of flowering, dormancy, and sprouting. Ecology 84:1199-1206

Sletvold N, Ågren J (2010) Pollinator-mediated selection on floral display and spur length in the orchid Gymnadenia conopsea. Int J Plant Sci 171:999-1009

Snow AA, Whigham DF (1989) Costs of flower and fruit production in Tipularia discolor (Orchidaceae). Ecology 70:1286-1293

Stearns SC (1992) The evolution of life histories. Oxford University Press, Oxford

Syrjänen K, Lehtilä K (1993) The cost of reproduction in Primula veris: differences between two adjacent populations. Oikos 67:465-472

Thompson FL, Eckert CG (2004) Trade-offs between sexual and clonal reproduction in an aquatic plant: experimental manipulations vs. phenotypic correlations. J Evol Biol 17:581-592

van Noordwijk AJ, de Jong G (1986) Acquisition and allocation of resources: their influence on variation in life history tactics. Am Nat 128:137-142

Velando A, Alonso-Alvarez C (2003) Differential body condition regulation by males and females in response to experimental manipulations of brood size and parental effort in the blue-footed booby. J Anim Ecol 72:846-856

Wells TCE, Willems JH (1991) Population ecology of terrestrial orchids. SPB, The Hague

Worley AC, Harder LD (1996) Size-dependent resource allocation and costs of reproduction in Pinguicula vulgaris (Lentibulariaceae). J Ecol 84:195-206 